\title{
Acute tryptophan depletion improves performance and modulates the BOLD response during a Stroop task in healthy females
}

Citation for published version (APA):

Evers, E. A. T., van der Veen, F. M., Jolles, J., Deutz, N. E., \& Schmitt, J. A. J. (2006). Acute tryptophan depletion improves performance and modulates the BOLD response during a Stroop task in healthy females. Neuroimage, 32(1), 248-255. https://doi.org/10.1016/j.neuroimage.2006.03.026

Document status and date:

Published: 01/01/2006

DOI:

10.1016/j.neuroimage.2006.03.026

Document Version:

Publisher's PDF, also known as Version of record

Please check the document version of this publication:

- A submitted manuscript is the version of the article upon submission and before peer-review. There can be important differences between the submitted version and the official published version of record.

People interested in the research are advised to contact the author for the final version of the publication, or visit the DOI to the publisher's website.

- The final author version and the galley proof are versions of the publication after peer review.

- The final published version features the final layout of the paper including the volume, issue and page numbers.

Link to publication

\footnotetext{
General rights rights.

- You may freely distribute the URL identifying the publication in the public portal. please follow below link for the End User Agreement:

www.umlib.nl/taverne-license

Take down policy

If you believe that this document breaches copyright please contact us at:

repository@maastrichtuniversity.nl

providing details and we will investigate your claim.
}

Copyright and moral rights for the publications made accessible in the public portal are retained by the authors and/or other copyright owners and it is a condition of accessing publications that users recognise and abide by the legal requirements associated with these

- Users may download and print one copy of any publication from the public portal for the purpose of private study or research.

- You may not further distribute the material or use it for any profit-making activity or commercial gain

If the publication is distributed under the terms of Article 25fa of the Dutch Copyright Act, indicated by the "Taverne" license above, 


\title{
NeuroImage
}

\section{Acute tryptophan depletion improves performance and modulates the BOLD response during a Stroop task in healthy females}

\author{
E.A.T. Evers, ${ }^{\text {a,* }}$ F.M. van der Veen, ${ }^{b}$ J. Jolles, ${ }^{a}$ N.E.P. Deutz, ${ }^{c}$ and J.A.J. Schmitt ${ }^{\mathrm{d}}$ \\ ${ }^{a}$ Department of Psychiatry and Neuropsychology (DRT 10), Brain and Behaviour Institute, Maastricht University, \\ P.O. Box 616, 6200 MD Maastricht, Netherlands \\ ${ }^{\mathrm{b}}$ Department of Psychiatry, Erasmus Medical Centre, Rotterdam, Netherlands \\ ${ }^{\mathrm{c}}$ Department of Surgery, Maastricht University, Maastricht, Netherlands \\ ${ }^{\mathrm{d} D e p a r t m e n t ~ N u t r i t i o n}$ and Health, Nestlé Research Centre, Lausanne, Switzerland
}

Received 3 February 2006; revised 7 March 2006; accepted 14 March 2006

Available online 2 May 2006

\begin{abstract}
To gain more insight into the effect of low brain serotonin (5-HT) on brain activation related to conflict, the present study examined the effect of acute tryptophan depletion (ATD) on performance and the blood oxygen level dependent (BOLD) response during a combined cognitive and emotional Stroop task. Fifteen healthy female volunteers were tested during a placebo and tryptophan depletion session in an event-related fMRI design. ATD improved performance during Stroop interference. Two effects of ATD on the BOLD response were found. Firstly, ATD increased the BOLD response in the anterior cingulate cortex (ACC) (BA 32) when incongruent color words were compared with congruent color words in the first Stroop block the participants performed. Secondly, ATD increased the BOLD response in the left precuneus (BA 31) and cuneus (BA 18) during congruent color words. ATD did not affect the BOLD response accompanying emotional stimuli. However, we showed that ATD increased the interference of negative words on color naming. This finding was explained in terms of an emotional processing bias in favor of negative words, which leads to stronger interference of these words. In line with previous studies, the present study showed that a temporary reduction of 5-HT improved Stroop performance and changed the underlying brain activation pattern in healthy female participants. Moreover, we replicated our previous finding that ATD modulated the BOLD response in the dorsomedial prefrontal cortex during tasks that require cognitive control.
\end{abstract}

(C) 2006 Elsevier Inc. All rights reserved.

Keywords: Serotonin; Acute tryptophan depletion; Stroop task; Functional MRI

\section{Introduction}

Acute tryptophan depletion (ATD) has been used as a model to study the effects of reduced central 5-HT (Nishizawa et al., 1997; Williams et al., 1999; Young et al., 1999) on cognitive performance

\footnotetext{
* Corresponding author. Fax: +31 433884092.

E-mail address: 1.evers@np.unimaas.nl (E.A.T. Evers).

Available online on ScienceDirect (www.sciencedirect.com).
}

and brain activation. In a previous study, our group showed that ATD increased the response in the dorsomedial prefrontal cortex (dmPFC) to negative feedback preceding a switch in response strategy (Evers et al., 2005). Activation in the dmPFC associated with negative feedback has been related to performance monitoring and cognitive control (see Ridderinkhof et al., 2004 for a review). According to one theory (Holroyd and Coles, 2002), the dmPFC response to negative feedback is linked to phasic changes in the midbrain dopamine system related to outcomes that are worse than expected. According to a second theory, dmPFC activation is related to conflict monitoring which becomes necessary when two competing response tendencies become active at the same time (Botvinick et al., 2004). In our previous study (Evers et al., 2005), it was unclear whether the dmPFC response to negative feedback was associated with an outcome that was worse than expected or conflict monitoring. Therefore, the present study examined brain responses to conflict in the absence of negative outcome. This was done in a combined cognitive and emotional Stroop task.

The studies examining the effects of ATD on performance in a Stroop task have been inconclusive thus far. Some studies reported improved performance (Coull et al., 1995; Rosse et al., 1992; Rowley et al., 1997; Schmitt et al., 2000), whereas other studies did not show an effect of ATD on Stroop performance (Gallagher et al., 2003; Horacek et al., 2005; Sobczak et al., 2002). Horacek et al. (2005) showed that ATD increased the blood oxygen level dependent (BOLD) response in the left bilateral mediofrontal, anterior cingulate and dorsolateral prefrontal cortex during Stroop performance in healthy volunteers. A problem with this study is that performance was measured outside the MRI scanner. It is therefore not possible to judge whether the participants carried out the task correctly during scanning. The current study used an event-related design to study the effect of ATD on the BOLD response during Stroop interference. Performance and the BOLD signal were recorded simultaneously.

5-HT has also been related to emotional processing. Previous studies revealed that ATD impaired the processing of positive 
information in healthy volunteers (Murphy et al., 2002) and remitted depressed patients (Booij et al., 2005). However, Booij et al. (2005) showed no effect of ATD on reaction times (RTs) and interference scores during an emotional Stroop task in currently depressed patients. In general, participants experience more interference from negative than from positive or neutral words (e.g. McKenna and Sharma, 1995) which can be explained by the higher threat caused by negative events in daily live (Mandler, 1975; Oatley and Johnson-Laird, 1987). Compton et al. (2003) showed that ignoring negative versus neutral words activated the bilateral occipito-temporal cortex and decreased the activation in the amygdala. Whalen et al. (1998) reported greater activation in the anterior cingulate cortex (ACC) for negative versus neutral words. However, Compton et al. (2003) did not find brain activation differences between positive and neutral words. To our knowledge, the present study is the first study examining the effect of ATD on the BOLD response during an emotional Stroop task.

To study the effect of ATD on cognitive Stroop interference and interference by emotional words, we designed a combined Stroop task in which congruent color (CC), incongruent color (IC), neutral (e.g. house, bean, coin), positive (e.g. proud, friend, smart) and negative (e.g. murder, bitch, death) words were presented in a semi-randomized order. Based on the studies discussed above, we hypothesized that (i) IC words cause more interference than CC words, (ii) IC words are associated with an increased BOLD response in the ACC, inferior parietal cortex, inferior frontal junction and middle frontal cortex (Laird et al., 2005) and (iii) ATD does not change or decreases Stroop interference and modulates the related BOLD response. With regard to the emotional Stroop part, we hypothesized that (i) RTs are higher for negative than for positive or neutral words because of the higher threat caused by negative events, (ii) the medial PFC, ACC and insula are activated during emotional words (for a review, see Phan et al., 2002) and (iii) ATD impairs performance on emotional words and affects the related brain activation.

\section{Materials and methods}

\section{Participants}

Nineteen healthy female volunteers (aged between 19 and 33; mean age 22.3; SE of mean 0.7 ), mostly pregraduate students, were included in this study, which was approved by the Medical Ethics Committee of Maastricht University Hospital. Participants were recruited by local advertisements. The health status of the participants was checked by a medical questionnaire, which was evaluated by a medical doctor. The participants received no medication at the moment of inclusion, had never used antidepressants or ecstasy, did not have a family history of affective disorder and were screened for MRI contra-indications. All participants gave written informed consent and were paid 75 euros.

\section{Experimental design}

Participants were scanned at the Maastricht University Hospital radiology department on two separate test days in an experimental and a placebo test session, counterbalanced according to a doubleblind crossover design. Participants arrived in the morning, after they had fasted overnight and eaten a low protein breakfast, and were given a tryptophan-depleted (TRP-) or a balanced (BAL) amino acid (AA) mixture followed by a $4.5 \mathrm{~h}$ break. During this break, only low protein food and protein and caffeine-free drinks were consumed. After the break (between 2 and 8.30 p.m.), the participants were scanned while performing two blocks of an emotional Stroop task, each lasting about 9 min. Halfway through the scanning session, a structural scan was made, which lasted for about $10 \mathrm{~min}$. Before the first test session, participants were trained in a dummy scanner.

\section{Stroop task}

The participants were instructed to report the color of the ink in which the presented words were printed by pressing one of four response buttons. Two fiber-optic response devices with two buttons were used. On the first response box, the left middle finger was used for blue, the left index finger for red. On the second response box, the right index finger was used for green, and the right middle finger for yellow. This color-response correspondence was written in small white letters on the bottom of the screen, along with each presented word. The participants were instructed to learn this correspondence by heart and to look at the bottom of the screen only if their memory failed. The task was programmed in E-Prime V1.0 (Psychology Software Tools, 2002). A word was presented every $2 \mathrm{~s}$ against a black background and stayed on the screen until a response was given. A black screen was shown between the response and the next stimulus. No feedback was given.

Participants completed two blocks of the modified Stroop task in each test session. Each block contained 40 CC, 40 IC, 24 positive, 24 negative and 24 neutral words, which were presented in a semi-randomized order (never the same color three times in a row). Each word type was presented equally often in each of the four colors. A test block started with 10 neutral words that were not included in the analysis. During the training session, the participants performed two Stroop blocks each containing 40 CC, 40 IC and 72 neutral words.

The following performance measures were used: mean RT and the number of errors for IC, CC, neutral, positive and negative words and interference scores. Interference scores for the cognitive Stroop express the extra time needed for IC compared with CC words ((RT for IC words - RT for CC words) / RT for CC words) as a percentage. As regards the emotional Stroop, interference scores were calculated for positive compared with neutral words and for negative compared with neutral words (Booij et al., 2005).

\section{Acute tryptophan depletion}

The present study used ATD to temporary lower 5-HT in the human brain (Young et al., 1985). The TRP- mixture (75 g) contained $4.1 \mathrm{~g}$ L-alanine, $2.4 \mathrm{~g}$ L-glycine, $2.4 \mathrm{~g}$ L-histidine, $6.0 \mathrm{~g}$ L-isoleucine, $10.1 \mathrm{~g}$ L-leucine, $6.7 \mathrm{~g}$ L-lysine, $4.3 \mathrm{~g}$ L-phenylalanine, $9.2 \mathrm{~g}$ L-proline, $5.2 \mathrm{~g}$ L-serine, $4.9 \mathrm{~g}$ L-threonine, $5.2 \mathrm{~g} \mathrm{~L}$ tyrosine, $6.7 \mathrm{~g}$ L-valine, $3.7 \mathrm{~g}$ L-arginine, $2.0 \mathrm{~g} \mathrm{~L}$-cysteine and $2.3 \mathrm{~g}$ L-methionine. In the BAL mixture, $3.0 \mathrm{~g}$ TRP was added. The mixtures were prepared with $200 \mathrm{ml}$ tap water.

\section{Biochemical measures}

Blood samples $(10 \mathrm{ml})$ were taken before ingestion of the AA mixture and about 15 min before the start of the scanning session to determine the plasma TRP level and the TRP/ $\sum$ LNAA ratio $([\mathrm{TRP}] /$ [tyrosine + leucine + phenylalanine + isoleucine + 
valine]). Blood samples were immediately centrifuged at $4^{\circ} \mathrm{C}(10$ min, $4500 \mathrm{rpm}$ ). One hundred microliters aliquot of plasma was mixed with $8 \mathrm{mg}$ sulfasalicyl acid and frozen at $-80^{\circ} \mathrm{C}$ until determination of the AAs by high-performance liquid chromatography (Van Eijk et al., 1993).

\section{Questionnaires}

\section{Mood}

A short visual analogue version of the Profile of Mood States (POMS) was used to assess mood (McNair et al., 1988). This questionnaire consists of 32 bipolar sets of adjectives, which measure five mood dimensions: anger, depression, fatigue, tension and vigor. The items were scored on a 10-point scale.

\section{Adverse effects}

Adverse effects, 31 items, were registered and scored on a 4point scale from 'no complaint at all' (0) to 'severe complaint' (4). A total score was calculated by adding the scores on the individual items.

\section{Statistical analysis}

The effect of ATD on the RTs and the number of errors were analyzed (SPSS version 11.5 for Windows) using GLM repeated measurements with Trial Type (IC and CC, or neutral, positive and negative words) and Treatment (BAL or TRP-) as within subject factors and Order (TRP - or BAL mixture first) as between-subject factor. The effect of ATD on interference scores was analyzed using GLM repeated measures with Treat as within subject variable and Order as between subject variable. Plasma TRP level and the $\mathrm{TRP} / \sum \mathrm{LNAA}$ ratio were analyzed using GLM repeated measurements with Time (t0 and t5) and Treatment as within subject variables and Order as between subject variable (GreenhouseGeisser correction). Paired-sample $t$ tests were used to compare baseline measurements. The effect of ATD on mood and adverse effects was analyzed using GLM repeated measurements with Time and Treatment as within subject variables and Order as between subject variable (Greenhouse-Geisser correction).

\section{Image acquisition}

Participants were scanned in a $1.5 \mathrm{~T}$ Philips scanner at the Maastricht University Hospital. T2*-weighted gradient echo planer images $(\mathrm{EPI})(\mathrm{TE}=27 \mathrm{~ms})$ were acquired with BOLD contrasts. A whole brain acquisition consisted of 24 slices (slice thickness $5 \mathrm{~mm}$; $\mathrm{TR}=1.75 \mathrm{~s}$; voxel size before normalization was $3.5 \times 3.5 \times 5 \mathrm{~mm}$ and after normalization $2 \times 2 \times 2 \mathrm{~mm}$; no slice gap; matrix size $64 \times$ $64 \times 24$; oblique transversal orientation; flip angle $90^{\circ}$ ), and 220 volumes were acquired for each Stroop block. The stimulus presentation and the scanning were synchronized at the beginning of each run. High-resolution T1-weighted images for anatomical localization were made of each participant (voxel size $1 \times 1 \times 1 \mathrm{~mm}$ ).

\section{Image analysis}

SPM2 (Wellcome Department of Cognitive Neurology, London, UK) was used for data processing. Preprocessing procedures included slice acquisition time correction (slice 12 as reference slice; $\mathrm{TA}=1.68$ ) and within subject realignment (Realign and Unwrap) using the first slice as a reference. Images from session 2 were then coregistered to the mean image from session 1 and thereafter spatially normalized to the standard Montreal Neurolog- ical Institute (MNI) structural template (average of $152 \mathrm{~T} 1$ brains). Finally, the images were spatially smoothed using a Gaussian (8 $\mathrm{mm}$ full-width at half maximum) kernel and high pass filtered (128 $\mathrm{s})$. A simple hemodynamic response was used as a covariate in a general linear model, and a parametric estimate was generated for each voxel for each trial type (correct and incorrect). Individual contrast images were taken to a second level analysis, in which $t$ values were calculated for each voxel treating inter-subject variability as a random effect. The hemodynamic response function was modeled to the onset of the response.

The following contrasts were calculated to assess task effects (BAL data only): 1) IC words versus all other trial types, 2) CC words versus all other trial types, 3) IC minus CC words, 4) neutral words versus all other trial types, 5) positive words versus all other trial types, 6) negative words versus all other trial types, 7) positive minus neutral words, 8) negative minus neutral words. These contrasts were analyzed using whole brain analysis $(P$-corrected cluster $<0.05)$.

The following contrasts were calculated to assess the effect of ATD: 9) IC words in the TRP - compared with IC words the BAL condition (IC words $\times$ ATD), 10) CC words $\times$ ATD, 11) [IC minus CC words $] \times$ ATD , 12) neutral words $\times$ ATD, 13) positive words $\times$ ATD, 14) negative words $\times$ ATD, 15) [positive minus neutral words] $\times$ ATD, 16) [negative minus neutral words] $\times$ ATD, 17) all events (IC, CC, neutral, positive and negative words) $\times$ ATD.

The effect of ATD was analyzed using whole brain analysis $(P$ corrected cluster $<0.05)$. ROI analyses were executed for the IC words (contrasts 9 and 11) using the following ROIs: brain areas that showed increased activation after ATD during a Stroop task as revealed by Horacek et al. (2005): the left inferior frontal gyrus (BA 47; TAL: $x=-24, y=12, z=-16$ ) and the right medial frontal gyrus (BA 10; TAL: $x=6, y=52, z=0$ ). We use WFUPickAtlas tool (Maldjian et al., 2003) for ROI analysis. Tenmillimeter spheres were built around the center coordinates. The Talaraich Daemon was used to label the coordinates of the anatomical regions (http://ric.uthscsa.edu/TDapplet/).

\section{Results}

Fifteen volunteers were successfully tested. Of the original 19 included volunteers, two dropped out after the first session because of nausea and vomiting, one volunteer panicked in the scanner, and imaging data for one participant were lost due to technical problems. Nine participants started in the BAL condition and six started in the TRP - condition.

\section{Biochemical results}

Blood samples were not complete for five participants due to technical problems. Data are presented for ten participants. ATD lowered $(F(1,8)=24.8 ; P=0.001)$ the TRP plasma level by $80 \%$. Mean TRP level on the BAL condition was $43.7 \mu \mathrm{M}(\mathrm{SE}=1.8)$ at t0 and $132.0 \mu \mathrm{M}(\mathrm{SE}=13.2)$ at $\mathrm{t} 5$. Mean TRP levels in the TRPcondition were $46.0 \mu \mathrm{M}(\mathrm{SE}=3.1)$ at $\mathrm{t} 0$ and $9.2 \mu \mathrm{M}(\mathrm{SE}=0.7)$ at t5. No significant difference in plasma TRP $(T=-1.1 ; P=0.3)$ was present at baseline (t0) between the BAL and the TRPcondition. ATD lowered $(F(1,8)=13.6 ; P<0.01)$ the TRP/ $\sum$ LNAA ratio by $91 \%$. The mean ratio in the BAL condition was $0.12(\mathrm{SE}=0.01)$ at $\mathrm{t} 0$ and $0.14(\mathrm{SE}=0.01)$ at $\mathrm{t} 5$. The mean ratio in the TRP - condition was $0.12(\mathrm{SE}=0.01)$ at $\mathrm{t} 0$ and $0.01(\mathrm{SE}=$ 
Table 1

Performance data: mean reaction times $(\mathrm{ms})$, the percentage incorrect responses per word type and the interference scores, with errors of the mean

\begin{tabular}{llcl}
\hline & Event type & BAL condition & TRP-condition \\
\hline Mean reaction time & incon & $768(24)$ & $736(20)$ \\
& con & $650(16)$ & $636(16)$ \\
& neu & $705(29)$ & $694(25)$ \\
& pos & $687(26)$ & $698(26)$ \\
Interference (\%) & neg & $717(28)$ & $705(30)$ \\
& incon versus con & $19(2)$ & $13(2)$ \\
& pos versus neu & $-2.3(1)$ & $0.5(1)$ \\
Percentage errors & neg versus neu & $1.9(1)$ & $1.4(1)$ \\
& incon & $7.5(0.6)$ & $9.0(0.8)$ \\
& con & $3.3(0.4)$ & $4.2(0.5)$ \\
& neu & $4.8(0.4)$ & $3.0(0.3)$ \\
& pos & $4.8(0.3)$ & $4.8(0.4)$ \\
& neg & $3.8(0.3)$ & $8.3(0.4)$ \\
\hline
\end{tabular}

$0.01)$ at $\mathrm{t} 5$. No significant difference $(T=0.9 ; P=0.4)$ in the ratio was present at baseline between the $\mathrm{BAL}$ and the TRP- condition.

\section{Performance}

\section{Cognitive Stroop}

RTs and percentage incorrect responses for the different event types are presented in Table 1. GLM analysis showed a main effect of Trial Type for RT $(F(1,13)=61.2 ; P<0.001)$ : participants responded slower on IC than on CC words. No main effect of ATD was found on RTs $(F(1,13)=1.2 ; P=0.30)$. Statistical analysis did not show an effect of ATD on the number of error on IC and CC words. GLM analyses revealed an effect of ATD on the interference score for IC words $(F(1,13)=4.5 ; P=0.057)$. Because of our a priori hypothesis that ATD does not change or decrease Stroop interference, it is allowed to test this hypothesis one-sided. We therefore concluded that ATD significantly de- creased $(F(1,13)=4.5 ; P=0.03)$ interference for IC words compared with $\mathrm{CC}$ words. This effect was not confounded by the order of testing $(F(1,13)=0.4 ; P=0.5)$.

\section{Emotional Stroop}

RTs and percentage incorrect responses for the different event types are presented in Table 1. GLM analysis showed a main effect of Emotion on RT $(F(1,13)=3.9 ; P<0.05)$. Paired $t$ tests showed that participants reacted slower to negative $(711 \mathrm{~ms}, \mathrm{SE}=26)$ than to positive $(693 \mathrm{~ms}, \mathrm{SE}=25 ; T=2.2 ; P<0.05)$ and neutral words (700 ms, $\mathrm{SE}=28 ; T=2.6 ; P<0.05)$. RTs for positive and neutral words did not differ. No effect of ATD on RTs was found. GLM analysis showed a significant interaction between Treatment and Emotion $(F(2,26)=9.8 ; P<0.01)$ for the number of errors. Paired $t$ tests showed that the numbers of errors on negative words increased after ATD $(T=3.2 ; P<0.01)$. No effect of ATD on the interference scores was found.

\section{Imaging}

\section{Cognitive Stroop}

Task-related BOLD responses during the BAL condition are presented in Table 2. IC words (contrast 1) were associated with an increased BOLD response in the left inferior parietal cortex (BA 40 ), left middle frontal cortex (BA 46) and right superior temporal cortex (BA 22). CC words (contrast 2) increased the BOLD response in the left inferior parietal (BA 40) and the right inferior frontal cortex (BA 45). IC minus CC words (contrast 3) was associated with an increased BOLD response in a left inferior frontal cluster (BA 44/45).

Since previous research (Compton et al., 2003; Bush et al., 1998) suggested that ACC activation is especially prone to the effects of practice, we conducted a post hoc analysis and investigated the BOLD response associated with IC minus CC words in the ACC (TD label bilateral anterior cingulate as ROI) in

Table 2

Brain areas activated during the different words types in the BAL condition revealed by whole brain analysis

\begin{tabular}{|c|c|c|c|c|c|c|}
\hline & Hemisphere & MNI coordinates & $T$ value & $P$-corrected cluster & Number of voxels & BA \\
\hline \multicolumn{7}{|l|}{ IC words } \\
\hline Inferior parietal cortex & Left & $(-50,-34,48)$ & 6.23 & 0.021 & 190 & 40 \\
\hline Middle frontal cortex & Left & $(-34,32,34)$ & 5.80 & 0.001 & 324 & 9 \\
\hline Superior temporal cortex & Right & $(52,14,-4)$ & 4.97 & 0.027 & 179 & 22 \\
\hline \multicolumn{7}{|l|}{ CC words } \\
\hline Inferior parietal cortex & Left & $(-52,-34,48)$ & 6.44 & 0.012 & 212 & 40 \\
\hline Inferior frontal cortex & Right & $(58,20,2)$ & 5.14 & 0.046 & 152 & 45 \\
\hline \multicolumn{7}{|l|}{ IC minus CC words } \\
\hline \multirow[t]{2}{*}{ Inferior frontal cortex } & Left & $(-40,24,26)$ & 6.89 & 0.002 & 279 & 45 \\
\hline & Left & $(-38,10,22)$ & 5.62 & & & 44 \\
\hline \multicolumn{7}{|c|}{ IC minus CC words first Stroop block } \\
\hline \multicolumn{7}{|c|}{ ROI analysis } \\
\hline Anterior cingulate cortex & Bilateral & $(0,36,22)$ & 4.83 & 0.044 & 27 & 32 \\
\hline \multicolumn{7}{|l|}{ Positive words } \\
\hline Inferior temporal cortex & Left & $(-46,-26,-22)$ & 5.72 & 0.012 & 203 & 20 \\
\hline \multicolumn{7}{|l|}{ Negative words } \\
\hline Postcentral cortex & Left & $(-44,-32,46)$ & 5.56 & 0.015 & 223 & 2 \\
\hline
\end{tabular}

$\mathrm{CC}=$ congruent color words, $\mathrm{IC}=$ incongruent color words, $\mathrm{BA}=$ Brodmann area. 
Table 3

Areas in which ATD increased the BOLD response during the cognitive Stroop task

\begin{tabular}{|c|c|c|c|c|c|}
\hline & MNI coordinates & $T$ value & $P$ corrected cluster & Number of voxels & Brodmann area \\
\hline \multicolumn{6}{|c|}{ IC minus CC words 1st Stroop block (ROI analysis) } \\
\hline Anterior cingulate cortex & $(0,36,22)$ & 4.37 & 0.023 & 9 & 32 \\
\hline \multicolumn{6}{|c|}{ CC words (whole brain analysis) } \\
\hline Left precuneus & $(-4,-68,18)$ & 6.28 & 0.004 & 256 & 31 \\
\hline Left cuneus & $(-10,-74,14)$ & 6.12 & & & 18 \\
\hline
\end{tabular}

$\mathrm{CC}=$ congruent color words. $\mathrm{IC}=$ incongruent color words.

the first Stroop block the participants performed (for nine participants this was a BAL block, for six participants this was a TRP - block). The analysis showed an increased BOLD response in the ACC (BA 32) associated with Stroop interference.

The effects of ATD on the BOLD response during the cognitive part of the Stroop task are presented in Table 3. No effect of ATD was found during IC words (contrast 9). ATD increased the BOLD response in the left precuneus (BA 31) and cuneus (BA 18) during CC words (contrast 10) (see Fig. 1). Whole brain analysis did not reveal ATD effects for contrast 11. To calculate the effect of ATD on IC minus CC words in the first Stroop block the participants performed, we first used a whole brain two samples (BAL or TRP-) $t$ test in which the TRP - Stroop blocks performed first were compared with BAL Stroop blocks firstly performed. Whole brain analysis did not reveal significant effects of ATD. Secondly, an ROI analysis was conducted: a $10-\mathrm{mm}$ sphere was build around MNI $x=0, y=36, z=22$, which is the center coordinate of the task-related BOLD response in the first Stroop block. This analysis showed that ATD increased the BOLD response in the ACC (BA 32) in the first Stroop block the participants performed (see Fig. 2).

\section{Emotional Stroop}

Positive words (contrast 5) were associated with an increased BOLD response in the left inferior temporal cortex (BA 20) and negative words (contrast 6) with an increased BOLD response in the left postcentral cortex (BA 2) (see Table 1). No significantly increased BOLD response was found for neutral words (contrast
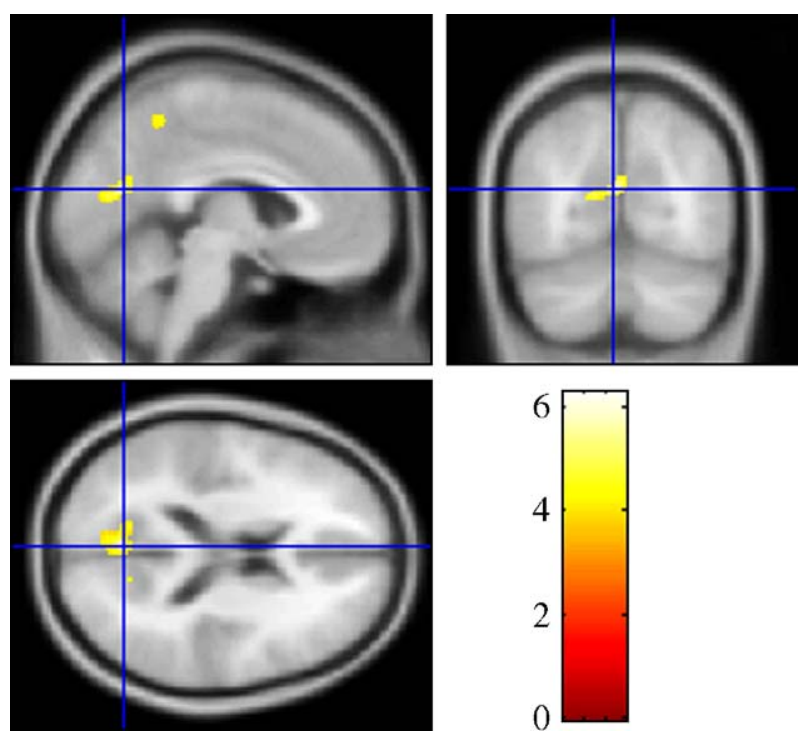

Fig. 1. Whole brain analysis revealed that ATD increase BOLD response in the left calcarine gyrus during congruent color words.
4), positive minus neutral words (contrast 7) and negative minus neutral words (contrast 8). No effect of ATD was found on the BOLD response during emotional words (contrast 12 until 16) and overall activation (contrast 17).

\section{Subjective measures}

On the POMS questionnaire, no effect of ATD was found on the subscales for depression $(F(1,13)=0.6 ; P=0.5)$, anger $(F(1,13)=$ $1.3 ; P=0.3)$, fatigue $(F(1,13)=4.0 ; P=0.1)$ and tension $(F(1,13)=$ $1.0 ; P=0.3)$. A significant main effect of Time $(F(1,13)=6.4 ; P<$ $0.05)$ and a significant interaction effects of Time $*$ Group $(F(1,13)=$ $6.4 ; P<0.05)$ and Treat * Time $(F(1,13)=5.6 ; P<0.05)$ were found for vigor: participants whose second session was the TRP- session felt less vigorous after ATD. No effect of ATD on physical complaints was found $(F(1,13)=0.1 ; P=0.7)$.

\section{Discussion}

The present study investigated the effect of ATD on performance and the BOLD response during a combined cognitive and emotional Stroop task. In the cognitive part of the Stroop task, we showed first that ATD increased the BOLD signal in the ACC when IC words were compared with $\mathrm{CC}$ words in the first block of the Stroop task. Secondly, ATD increased the BOLD response in the left precuneus (BA 31) and cuneus (BA 18) during CC words. At the behavioral level, ATD decreased the interference score for IC words. In the emotional part of the Stroop task, we showed that ATD increased the number of errors on negative words but did not change the BOLD response.

\section{Cognitive Stroop}

Largely in accordance with the results of a meta-analysis by Laird et al. (2005), we found an increased BOLD response in the left inferior parietal, middle frontal and the right superior temporal cortex related to IC words in the BAL condition. Interestingly, the current study did not find an increased BOLD response in the ACC during Stroop interference. A study carried out by Compton et al. (2003) also failed to find increased ACC activation during IC words. They suggested that this might be explained by practice effects and mention a study in their laboratory that showed increased ACC activation in the first, no ACC activation in the second and decreased ACC activation in the last third of a Stroop interference condition. Furthermore, Bush et al. (1998) showed that the relative difference in the ACC activity between the interference and the neutral conditions decreased as subjects learned the task. In the present study, the participants performed two blocks of the Stroop task during the practice session (80 IC 

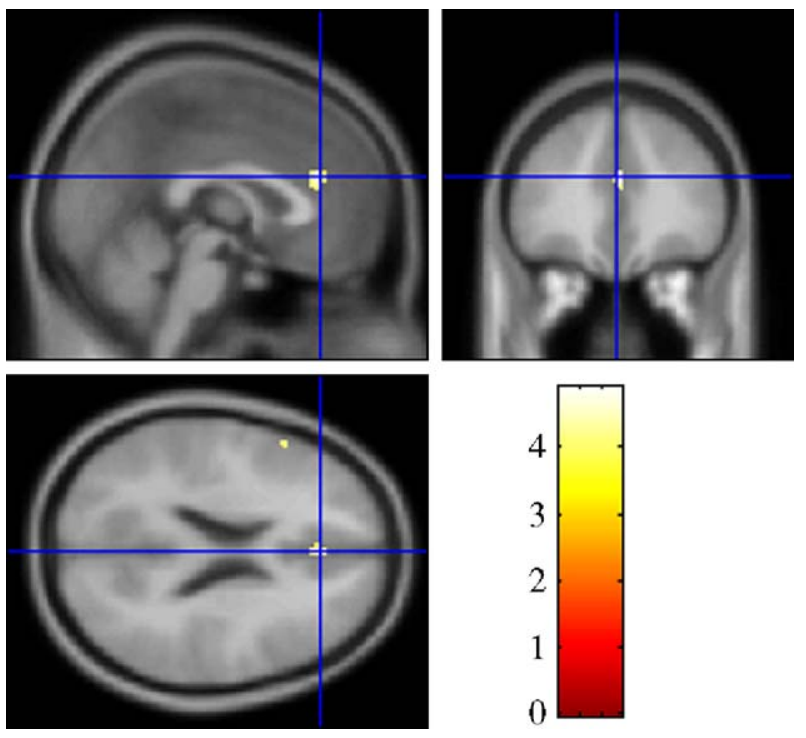

Fig. 2. Region of interest analysis revealed that ATD increased the BOLD response in the anterior cingulate cortex when color incongruent words were compared with color congruent words in the first Stroop block the participants performed.

trials), two in the BAL (80 IC trials) and two in the TRP - session (80 IC trials). A post hoc analysis revealed that the ACC was activated when IC words were compared with CC words in the first Stroop block the participants performed. This result confirms the hypothesis that practice decreased the BOLD response in the ACC.

Post hoc ROI analysis revealed that ATD increased the BOLD response in the ACC (BA 32) when IC words were compared with $\mathrm{CC}$ words in the first Stroop block the participants performed. Since the ACC has been related to conflict monitoring and signaling the need for more cognitive control (Botvinick et al., 1999, 2004; Ridderinkhof et al., 2004; Kerns et al., 2004; Matsumoto and Tanaka, 2004), we hypothesize that the increased ACC activation triggered more cognitive control and thereby improved performance during Stroop interference. This hypothesis needs to be tested by future research. In line with these findings, Horacek et al. (2005) reported an increased BOLD response in the ACC (BA 23) after ATD during the interference condition of a Stroop task.

The finding of an increased response in the dmPFC is in line with a previous study (Evers et al., 2005) in which we showed that ATD increased the BOLD response in the dmPFC to negative feedback preceding a switch in response strategy. It should be noted, however, that the center of the area with increased activation was located more ventrally in the present study ([MNI: $x=0, y=$ $36, z=22]$ vs. [MNI: $x=9, y=39, z=48]$ ). Based on a review study by Ridderinkhof et al. (2004), which showed that activation related to conflict is not only found in the ACC (BA 24 and 32) but also more dorsally (BA 6 and 8), we would like to speculate that the increased dmPFC response that was found in both studies possibly reflects the same underlying cognitive process. The response to IC trials as well as the response to negative feedback preceding a switch in response strategy might be related to conflict monitoring. In contrast, our research group found that ATD decreased the response in the dmPFC (BA 8; MNI: $x=0, y=$ $46, z=38$ ) after a response error followed by negative feedback in a Go/NoGo task in healthy male volunteers (unpublished data).
Talbot and Cooper (in press) showed that ATD reduced the activation in the dorsal ACC (BA 32; MNI: $x=-6, y=38, z=24$ ) in healthy participants at rest. The present data confirm the suggestion of these authors that the dmPFC might be related to the effect of ATD on cognition in healthy participants. Obviously, more research is needed to examine the seemingly complex association between reduced 5-HT, the dmPFC and cognition.

ATD increased the BOLD response in the left precuneus (BA 31 ) and cuneus (BA 18) during CC trials. Previous ATD studies (Booij et al., 2005; Gallagher et al., 2003; Horacek et al., 2005; Schmitt et al., 2000; Sobczak et al., 2002) did not examine CC words since these studies used the three-card version of the Stroop task. The present study used a modified Stroop task designed for event-related fMRI in which both IC and CC words were presented. We were therefore able to study the interference (slowing) and the facilitation (speeding) effect of the color name. ATD increased the BOLD response in the cuneus (BA 18; part of area V2) and the precuneus (BA 31; part of area V4) during CC words. These areas are part of the parvocellular path, which is important in color perception (for a review, see Gegenfurtner and Kiper, 2003). The present study suggests that ATD increases the BOLD response in brain areas related to color perception during the reading of $\mathrm{CC}$ words. It is noteworthy that ATD did not affect the performance on $\mathrm{CC}$ words.

\section{Emotional Stroop}

In accordance with our hypothesis, we showed that participants reacted slower to negative than to neutral or positive words. Despite these differences in RTs, we did not find differences in BOLD response between these emotionally salient words. Compton et al. (2003) reported that multiple pilot studies in their laboratory indicated that emotion-related brain activation only showed in a blocked design. It is likely that the presentation of the emotional words in the present study was too short to change the emotional state of the participants. Participants might have been distracted by these words, as shown in the RT data, without showing brain activity related to this emotional state.

Booij et al. (2005) showed that ATD increased interference levels for positive words on an emotional Stroop task. This increase was found in the high-dose ATD condition (100 g), but not in the low-dose ATD condition (50 g). The present study used a 75-g AA mixture, which can be seen as a medium dose. This might explain why the increase in interference levels for positive words was present in our study but did not reach significance $(F(1,13)=$ $2.1 ; P=0.17)$. Instead, the present study showed that ATD increased the number of errors on negative words. Unfortunately, Booij et al. (2005) did not report the number and kind of errors made during the emotional Stroop task. Studies that investigated the processing of emotional words in depressed patients (e.g. Lim and Kim, 2005; Rinck and Becker, 2005) are in line with our results. These patients often have an emotional processing bias in favor of negative words that are related to their relevant concerns (e.g. Nunn et al., 1997).

A limitation of the present study is that we used female volunteers only. Since previous studies showed that ATD affects females and males differently (Booij et al., 2002; Harmer et al., 2003), the results of the present study are representative for a female population only.

To conclude, the present study confirms the suggested role for 5-HT in response conflict. It showed that ATD improved Stroop 
performance and increased the BOLD response in the ACC in the first Stroop block. However, more research is needed to examine the association between low 5-HT, the dmPFC and cognition.

\section{Acknowledgments}

We thank Olga Reneerkens for test and analysis assistance and Jeroen van Deursen for radiographic assistance. This work was supported by a TOP grant (No. 912-02-050) from ZonMW-NWO and a grant from the Dutch Brain Foundation (Hersenstichting Nederland, 11F03(2).41).

\section{References}

Booij, L., Van der Does, W., Benkelfat, C., Bremner, J.D., Cowen, P.J., Fava, M., Gillin, C., Leyton, M., Moore, P., Smith, K.A., Van der Kloot, W.A., 2002. Predictors of mood response to acute tryptophan depletion. A reanalysis. Neuropsychopharmacology 27 (5), 852-861.

Booij, L., Van der Does, A.J., Haffmans, P.M., Riedel, W.J., Fekkes, D., Blom, M.J., 2005. The effects of high-dose and low-dose tryptophan depletion on mood and cognitive functions of remitted depressed patients. J. Psychopharmacol. 19 (3), 267-275.

Botvinick, M., Nystrom, L.E., Fissell, K., Carter, C.S., Cohen, J.D., 1999. Conflict monitoring versus selection-for-action in anterior cingulate cortex. Nature 402 (6758), 179-181.

Botvinick, M., Cohen, J.D., Carter, C.S., 2004. Conflict monitoring and anterior cingulate cortex: an update. Trends Cogn. Sci. 8 (12), $539-546$.

Bush, G., Whalen, P.J., Rosen, B.R., Jenike, M.A., Mc Inerney, S.C., Rauch, S.L., 1998. The counting Stroop: an interference and facilitation effects for functional neuroimaging. Validation study with functional MRI. Hum. Brain Mapp. 6, 270-282.

Compton, R., Banich, M.T., Mohanty, A., Milham, M.P., Herrington, J., Miller, G.A., Scalf, P.E., Webb, A., Heller, W., 2003. Paying attention to emotion: an fMRI investigation of cognitive and emotional Stroop tasks. Cogn. Affect. Behav. Neurosci. 3 (2), 81-96.

Coull, J.T., Sahakian, B.J., Middleton, H.C., Young, A.H., Park, S.B., McShane, R.H., Cowen, P.J., Robbins, T.W., 1995. Differential effects of clonidine, haloperidol, diazepam and tryptophan depletion on focused attention and attentional search. Psychopharmacology (Berlin) $121,222-230$

Evers, E.A., Cools, R., Clark, L., van der Veen, F.M., Jolles, J., Sahakian, B.J., Robbins, T.W., 2005. Serotonergic modulation of prefrontal cortex during negative feedback in probabilistic reversal learning. Neuropsychopharmacology 30 (6), 1138-1147.

Gallagher, P., Massey, A.E., Young, A.H., McAllister-Williams, R.H., 2003. Effects of acute tryptophan depletion on executive function in healthy volunteers. BMC Psychiatry 3 (10).

Gegenfurtner, K., Kiper, D.C., 2003. Color vision. Annu. Rev. Neurosci. 26, 181-206.

Harmer, C.J., Rogers, R.D., Tunbridge, E., Cowen, P.J., Goodwin, G.M., 2003. Tryptophan depletion decreases the recognition of fear in female volunteers. Psychopharmacology (Berlin) 167 (4), 411-417.

Holroyd, C.B., Coles, M.G., 2002. The neural basis of human error processing: reinforcement learning, dopamine, and the error-related negativity. Psychol. Rev. 109 (4), 679-709.

Horacek, J., Zavesicka, L., Tintera, J., Dockery, C., Platilova, V., Kopecek, M., Spaniel, F., Bubenikova, V., Hoschl, C., 2005. The effect of tryptophan depletion on brain activation measured by fMRI during the Stroop test in healthy volunteers. Physiol. Res. 54.

Kerns, J., Cohen, J.D., MacDonald, A.W., Cho, R.Y., Stenger, V.W., Carter, C.S., 2004. Anterior cingulate conflict monitoring and adjustments in control. Science 303, 1023-1026.
Laird, A.R., McMillan, K.M., Lancaster, J.L., Kochunov, P., Turkeltaub, P.E., Pardo, J.V., Fox, P.T., 2005. A comparison of label-based review and ALE meta-analysis in the Stroop task. Hum. Brain Mapp. 25 (1), $6-21$.

Lim, S., Kim, J.H., 2005. Cognitive processing of emotional information in depression, panic, and somatoform disorder. J. Abnorm. Psychology 114 (1), 50-61.

Maldjian, J.A., Laurienti, P.J., Kraft, R.A., Burdette, J.H., 2003. An automated method for neuroanatomic and cytoarchitectonic atlas-based interrogation of fMRI data sets. NeuroImage 19, 1233-1239.

Mandler, G., 1975. Mind and Emotion. Wiley, New York.

Matsumoto, K., Tanaka, K., 2004. Conflict and cognitive control. Science 303, 969-970.

McKenna, F.P., Sharma, D., 1995. Intrusive cognitions: an investigation of the emotional Stroop task. J. Exper. Psychol., Learn., Mem., Cogn. 21, $1595-1607$.

McNair, D.M., Lorr, D.M., Droppelman, L.F., 1988. Manual for the Profile of Mood States. Educational and Industrial Testing Service, San Diego, CA.

Murphy, F.C., Smith, K.A., Cowen, P.J., Robbins, T.W., Sahakian, B.J., 2002. The effects of tryptophan depletion on cognitive and affective processing in healthy volunteers. Psychopharmacology 163, 42-53.

Nishizawa, S., Benkelfat, C., Young, S.N., Leyton, M., Mzengeza, S., De Montigny, C., Blier, P., Diksic, M., 1997. Differences between males and females in rates of serotonin synthesis in human brain. Proc. Natl. Acad. Sci. U. S. A. 94, 5308-5313.

Nunn, J., Mathews, A., Trower, P., 1997. Selective processing of concern-related information in depression. Br. J. Clin. Psychol. 36 (Pt 4), 489-503.

Oatley, K., Johnson-Laird, P.N., 1987. Toward a cognitive theory of emotion. Cogn. Emot. 1, 29-50.

Phan, K.L., Wager, T., Taylor, S.F., Liberzon, I., 2002. Functional neuroanatomy of emotion: a meta-analysis of emotion activation studies in PET and fMRI. NeuroImage 16, 331-348.

Psychological Software Tools, 2002. E-Prime. http://www.pstnet.com.

Ridderinkhof, R.K., Ulsperger, M., Crone, E.A., Nieuwenhuis, S., 2004. The role of the medial frontal cortex in cognitive control. Science 306, $443-447$.

Rinck, M., Becker, E.S., 2005. A comparison of attentional biases and memory biases in women with social phobia and major depression. J. Abnorm. Psychology 114 (1), 62-74.

Rosse, R.B., Schwartz, B.L., Zlotolow, S., Banay-Schwartz, M., Trinidad, A.C., Peace, T.D., Deutsch, S.I., 1992. Effect of a low-tryptophan diet as an adjuvant to conventional neuroleptic therapy in schizophrenia. Clin. Neuropharmacol. 15 (2), 129-141.

Rowley, B., Van, F., Mortimore, C., Connell, J., 1997. Effects of acute tryptophan depletion on tests of frontal and temporal lobe function. J. Psychopharmacol. (Oxford) 11, A60.

Schmitt, J.A., Jorissen, B.L., Sobzak, S., van Boxtel, M.P., Hogervorst, E., Deutz, N.E., Riedel, W.J., 2000. Tryptophan depletion impairs memory consolidation but improves focussed attention in healthy young volunteers. Psychopharmacology 14 (1), 21-29.

Sobczak, S., Riedel, W.J., Booij, L., Aan Het Rot, M., Deutz, N.E., Honig, A., 2002. Cognition following acute tryptophan depletion: difference between first-degree relatives of bipolar disorder patients and matched healthy control volunteers. Psychol. Med. 32 (3), 503-515.

Talbot, P.S., Cooper, S.J., in press. Anterior cingulate and subgenual prefrontal blood flow changes following tryptophan depletion in healthy males. Neuropsychopharmacology.

Van Eijk, H.M., Rooyakkers, D.R., Deutz, N.E., 1993. Rapid routine in amino acids in plasma by high-performance liquid chromatography with a 2-3 microns spherisorb ODS 11 column. J. Chromatogr. 620 , $143-148$.

Whalen, P., Bush, G., McNally, R.J., Wilhelm, S., McInerney, S.C., Jenike, M.A., Rauch, S.L., 1998. Emotional counting Stroop paradigm: a functional magnetic resonance imaging probe of the anterior cingulate affective division. Biol. Psychiatry 44 (12), 1219-1228. 
Williams, W.A., Shoaf, S.E., Hommer, D., Rawlings, R., Linnoila, M., 1999. Effects of acute tryptophan depletion on plasma and cerebrospinal fluid tryptophan and 5-hydroxyindoleacetic acid in normal volunteers. J. Neurochem. 72, 1641-1647.

Young, S., Smith, S.E., Pihl, P.O., Ervin, F.R., 1985. Tryptophan depletion causes a rapid lowering of mood in normal males. Psychopharmacology 87, $173-177$.

Young, S.N., Leyton, M., Benkelfat, C., 1999. Pet studies of serotonin synthesis in the human brain. Adv. Exp. Med. Biol. 467 (11-18). 